\title{
When Mental IIIness and the Justice System Intersect
}

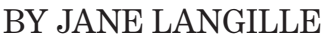

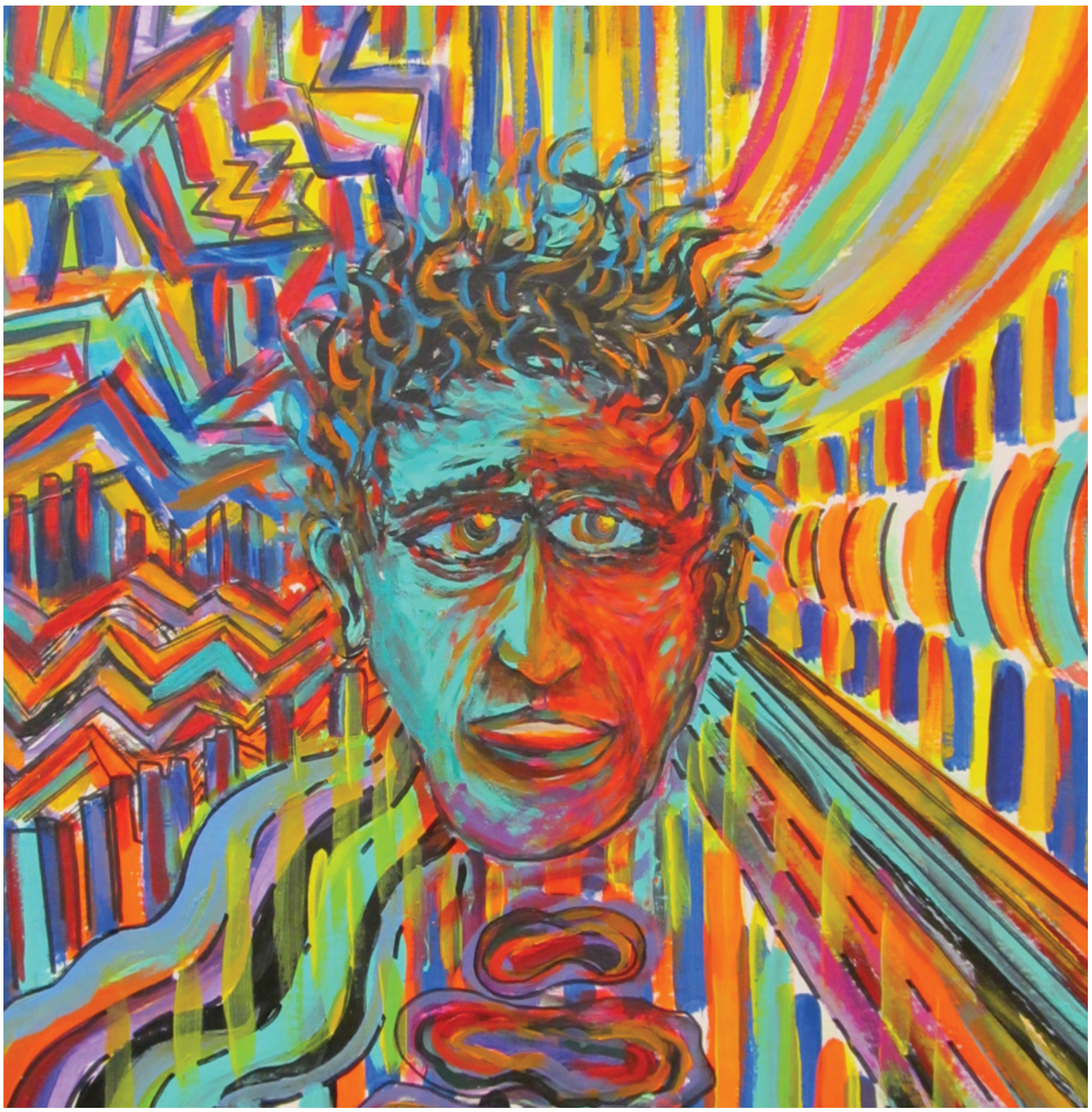

\section{My View from Inside}

"Walking across the High Level Bridge, overwhelming thoughts pushed me into thinking that I could not find solutions to my problems. I wanted to vanish, I was so confused and tormented." 
B rett Batten has been living with bipolar disorder with psychotic features for most of his 45 years. About 14 years ago, he came into contact with the law and spent three years in various jails before getting treatment for his mental illness. Batten says, "In jail, I was making disturbances because of my delusions, so they put me in 'the hole' [solitary confinement]. When the psychiatrist finally came to see me, he ordered my move to a medical cell. Only then did I receive the right medication and become aware of time and place."

A disproportionate number of people with mental illness get caught up in the justice system. In his annual report for 2011-2012, Howard Sapers, the Correctional Investigator of Canada, states that rates of serious mental health problems among federal offenders upon admission more than doubled between 1997 and 2008.

Patrick Baillie, a lawyer and a consulting psychologist with the Calgary Police Service and a member of the Mental Health Commission of Canada (MHCC) advisory council, says that there are marked inadequacies in how people with mental illness are handled by the justice system: "This notion of people falling through the cracks? They're not cracks. They're gaping crevasses."

Baillie comments that better coordination between the mental health system and the justice system is the single most important need for people living with mental health problems and illnesses involved with the law. The forensic division in which he works includes a mental health diversion program, through which offenders with mental illness are diverted pre-charge so that they can be assessed and receive treatment. Those who need support have access to physician referrals, emergency housing and medication. As a result, more people with mental illness stay out of jail. "Our program has some unique features, but the concept is not at all unique to Calgary."

One of the benefits of the diversion model is its cost-effectiveness: court costs are reduced because there are fewer hearings involving judges, prosecutors and lawyers; policing costs are lower because more people are assessed and supported before they get into crisis; and hospitalization costs are reduced because intervention typically occurs in outpatient settings. Baillie says the model also translates well to smaller communities, where social workers and other mental health professionals can work with local police to help people with mental illness access community support programs.

The role of nurses in the Calgary forensic outpatient programs is significant on several levels, Baillie says. "The nurses have their own client caseloads and provide individual therapy, monitor medication and act as community liaison. They may also assist psychologists and psychiatrists in conducting more formal assessments." Because they have ongoing relationships with clients, Baillie adds, the nurses also play a key role in assisting the provincial review board with decision-making [see sidebar].

Arlene Kent-Wilkinson, who worked in forensic and psychiatric nursing for 21 years, is an associate professor at the University of Saskatchewan. She led a research team that recently conducted a province-wide needs assessment of programs and services for offenders with mental disorders. Too many, she says, are incarcerated without being assessed. "It's not people with extreme mental illness that slip through. It's those who are marginal or who have addiction problems."

Once in correctional facilities, people with mental illness have limited treatment alternatives available. Baillie cites issues such as understaffing, budget cutbacks and policies that don't allow certain prescribed medications over concerns about addiction, making it difficult for those who need medication to follow

\section{Understanding the Criminal Code mental disorder regime}

Under Canadian criminal law, if an accused cannot understand the nature of the trial and its consequences and cannot communicate with his/her lawyer due to a mental disorder, the court will find that the person is unfit to stand trial. Later, if the person becomes fit to stand trial, he/she is then tried for the offence.

If a person commits an offence but lacks the capacity to understand what he/she did, or that it was wrong, due to a mental disorder at the time, the court will find the person "not criminally responsible on account of mental disorder"(NCRMD). He/she is neither acquitted nor convicted.

Those found either unfit to stand trial or NCRMD are referred to a provincial or territorial review board that makes one of three possible decisions: absolute discharge - only for those found NCRMD and if they do not pose a threat to society, conditional discharge or detention in custody in a hospital. 


\section{People living with mental health problems and illnesses are more likely to be victims of violence than perpetrators of crime}

\section{MHCC initiatives}

- The MHCC recently partnered with the Canadian Association of Chiefs of Police to sponsor a two-day conference to find ways to improve interactions between police and people living with mental health problems or illnesses. Review the key recommendations contained in A Comprehensive Review of the Preparation and Learning Necessary for Effective Police Interactions with Persons with a Mental IIIness, which was released at the conference.

- While much is known about how police perceive people with mental illness, less is understood about how people with lived experience perceive the police. Read the report of an MHCCfacilitated study of this issue that reveals several interesting trends.

- Learn more about the National Trajectory Project, which follows the path of individuals declared NCRMD through the mental health and criminal justice systems.

- View the fact sheet About the Not Criminally Responsible Due to a Mental Disorder (NCRMD) Population in Canada.

- Collaborative Spaces is a public community of individuals that share work, stories and resources. Sign up for a free account at mentalhealthcommission.ca/ mhcc-collaborative-spaces to discuss mental health and the law. treatment plans.

In his annual reports, Sapers has raised concerns about conditions of chronic overcrowding and called for an end to the practice of allowing prolonged segregation for offenders with mental illness. Referring to his own experiences, Batten comments, "Solitary confinement is an abusive practice that does nothing to improve behaviour and deprives people from getting treatment. It exacerbates mental illness and deteriorates mental wellness."

Discharges into the community may occur without treatment or support plans in place. Baillie says, "It's the individuals who are not receiving treatment that are taking up police services' time across the country." He has seen some people with mental illness who were released at 8:00 a.m. reoffend before the end of the day because dysfunctional coping mechanisms like substance abuse and theft are all they know.

Police have been referred to as de facto mental health care providers and the front-line extension of the mental health system. Although most police interactions with people living with mental illness are positive, a few are negative and a very few are tragic.

Police services across Canada have been investing in education and training and using new models of community safety to improve their responses and the outcomes to calls involving people with lived experience of mental illness. Partnerships with community mental health agencies have decreased negative incidents and improved interventions, averting crisis situations that are not only high risk but also labour intensive. There is also some evidence that these approaches can contribute to reducing the overrepresentation of people living with a mental illness in the criminal justice system, one of the key recommendations of Canada's first mental health strategy.

The MHCC's president and CEO, Louise Bradley, is a nurse who has worked in both forensic mental health and correctional settings. She says that while there are very promising solutions out there for dealing with these complex issues, there is a need for greater coordination.

"The bottom line is that we need to stop viewing this as a policing problem or a mental health problem - and start seeing it for what it is: a societal problem," says Bradley. "It's an issue that needs to be dealt with for the health of our communities as a whole."

After he was found NCRMD, Brett Batten was transferred to a forensic facility for two years, where he received his first exposure to comprehensive treatment. He says, "I look at the forensic system as one of the best and worst things to happen in my more than 30-year mental health journey. In the rehabilitation unit, I had an occupational therapist, a vocational therapist, a psychiatrist, a psychologist, a social worker and nursing staff." Ultimately, Batten was granted an absolute discharge to live in the community with no restrictions. He focuses his time on writing and speaking to help others dealing with mental illness.

JANE LANGILLE IS A HEALTH AND MEDICAL WRITER IN RICHMOND HILL, ONT.
About the artist:
Almier is a member of the Out of the Shadows Artists' Collective, an Edmonton community-based program that promotes recovery and wellness through the arts. For more information on the program, contact Erin Carpenter, occupational therapist, or Cathy McAlear, recreation therapist, from Alberta Health Services, Regional Mental Health at 780-342-7754. 